\title{
Estudio del uso de la poliamida como alternativa al algodón y la paja en soportes de colecciones de historia natural
}

\author{
Marta Plaza Beltrán, Oscar Luis Ramos Lugo, Jorge Rivas López
}

\begin{abstract}
Resumen: Los soportes para almacenamiento de colecciones de historia natural realizados con materiales como la madera, la resina, el papel, el cartón o el algodón pueden generar acidificación; sin olvidar las eventuales complicaciones que podrían derivarse del carácter polimatérico de los ejemplares, tanto por su naturaleza como por los materiales utilizados para su realización. Por tanto, al hablar de deterioro y acidificación, se deben contemplar los factores intrínsecos y extrínsecos. De este modo, contaminantes externos como el dióxido de azufre $\left(\mathrm{SO}_{2}\right)$, óxidos de nitrógeno $\left(\mathrm{NO}_{x}\right)$, ozono $\left(\mathrm{O}_{3}\right)$ o sulfuro de hidrógeno $\left(\mathrm{H}_{2} \mathrm{~S}\right)$, pueden interactuar con los contaminantes ácidos producidos por materiales dentro de los propios almacenes como el ácido acético $\left(\mathrm{CH}_{3} \mathrm{COOH}\right)$ y el ácido fórmico $(\mathrm{HCOOH})$, donde la humedad relativa y la temperatura favorecen o evitan una determinada reacción. En este contexto, el algodón y la paja han tenido un protagonismo indiscutible en soportes y relleno en taxidermia artística y científica. Aquí presentamos como alternativa de relleno una poliamida empleada en otros contextos: el Perlón ${ }^{\circledast}$.
\end{abstract}

Palabras clave: acidificación, algodón, conservación, fibras sintéticas, soportes, poliamida, Nylon ${ }^{\circledast}$, Perlón ${ }^{\circledast}$

\section{Study of the use of polyamide as an alternative to cotton and straw in supports of natural history collections}

Abstract: Storage supports for natural history collections made with materials such as wood, resin, paper, cardboard or cotton, they can generate acidification; without forgetting the effects that the polymeric nature of the specimens can produce, both due to their nature and the materials used to produce them. Therefore, intrinsic and extrinsic factors must be considered when speaking of deterioration and acidification. In this way, external pollutants such as sulfur dioxide $\left(\mathrm{SO}_{2}\right)$, nitrogen oxides $\left(\mathrm{NO}_{x}\right)$, ozone $\left(\mathrm{O}_{3}\right)$ or hydrogen sulfide $\left(\mathrm{H}_{2} \mathrm{~S}\right)$, can interact with acidic pollutants produced by materials within their own warehouses such as acetic acid $\left(\mathrm{CH}_{3} \mathrm{COOH}\right.$ and formic acid $(\mathrm{HCOOH})$, where relative humidity and temperature favor or avoid a certain reaction. In this context, cotton and straw have had an indisputable role in supports and fillers in artistic and scientific taxidermy. Here we present as a filling alternative a polyamide used in other contexts: Perlon ${ }^{\circledR}$.

Keywords: acidification, cotton, conservation, synthetic fibers, supports, polyamide, Nylon ${ }^{\circledR}$, Perlón ${ }^{\circledR}$

\section{Estudo do uso de la poliamida como alternativa ao algodão e palha em suportes de coleção de história natural}

Resumo: Os suportes para armazenamento de coleções de história natural feitos com materiais como madeira, resina, papel, papelão ou algodão, podem gerar acidificação; sem esquecer os efeitos que o caráter polimérico dos corpos-de-prova pode produzir, tanto pela sua natureza como pelos materiais com que foram fabricados. Portanto, quando se fala em deterioração e acidificação, devemos considerar fatores intrínsecos e extrínsecos. Desta forma, poluentes externos, como dióxido de enxofre $\left(\mathrm{SO}_{2}\right)$, óxidos de nitrogênio $\left(\mathrm{NO}_{x}\right)$, ozônio $\left(\mathrm{O}_{3}\right)$ ou sulfeto de hidrogênio $\left(\mathrm{H}_{2} \mathrm{~S}\right)$, podem interagir com os poluentes ácidos produzidos por materiais dentro dos próprios armazéns, como ácido acético $\left(\mathrm{CH}_{3} \mathrm{COOH}\right)$ e ácido fórmico $(\mathrm{HCOOH})$, onde a umidade relativa e a temperatura favorecem ou impedem uma determinada reação. Neste contexto, o algodão e a palha têm desempenhado um papel indiscutível de suportes e enchimentos na taxidermia artística e científica. Apresentamos aqui como alternativa de enchimento uma poliamida utilizada em outros contextos: Perlon ${ }^{\oplus}$.

Palavras-chave: acidificação, algodão, preservação, fibras sintéticas, suportes, poliamida, Nylon ${ }^{\circledast}$, Perlón ${ }^{\circledast}$ 


\section{Introducción}

El estudio presentado se ha realizado en el Museo Nacional de Ciencias Naturales (MNCN), centro de investigación integrado en la Agencia Estatal Consejo Superior de Investigaciones Científicas, CSIC, que alberga y conserva diversas colecciones científicas e históricas de historia natural de enorme valor por su reconocida calidad y prestigio nacional e internacional, tanto por el número de especímenes que las componen como por su relevancia científica e histórica.

Entre las Colecciones que custodia este Museo, la de Aves y la de Mamíferos, se conservan especímenes de historia natural desde finales del siglo XVIII, tanto en áreas de exhibición como en almacenes. Durante la segunda época del Museo, periodo donde se produjeron acontecimientos importantes para la institución, tiene lugar la Comisión Científica al Pacífico (1862-1866). En dicha expedición se colectaron numerosas especies, entre ellas grupos de aves y mamíferos. Concretamente, se recogieron 249 especies de mamíferos, 3.804 de aves y 204 nidos y huevos (Almagro 1866), lo que supone un gran tesoro científico a salvaguardar; siempre analizado desde el contexto histórico donde se generaron estas colecciones, en el cual la protección hacia el conjunto de la biodiversidad y sus especies no se contemplaba todavía.

Las Colecciones de Aves y Mamíferos que integran el almacén C-12, forman parte de las llamadas "colecciones en seco" por su método de conservación, pues los ejemplares no se guardan sumergidos en una solución conservante. Se encuentran clasificadas en tres grandes grupos atendiendo al material que contienen: pieles -tanto naturalizadas como ejemplares para estudio científico-, huesos y, por último, el grupo de "otras colecciones en seco", como la de Oología, llamada así al estar compuesta por nidos y huevos de aves
(Barreiro et al. 1994: 26-30; Barreiro et al. 2019: 235-252). Este tipo de colecciones en seco se utilizan en trabajos de etología, análisis de pesticidas, morfología y estudios citogenéticos. Las colecciones en seco aquí estudiadas se preparan eliminando todos los materiales y tejidos que puedan ser un foco de proliferación de microorganismos en las pieles y huevos. Las pieles están tratadas conácidos y sales para curtirlas (bórax, sales, taninos, etc.) (Aragón 2005: 3238), aplicándoles grasa finalmente para poderlas manipular, otorgándoles elasticidad sin romperse. Si a lo anterior se le suman los elementos estructurales realizados con todo tipo de materiales (madera, metal, plástico, fibras vegetales, etc.), y productos empleados para su naturalización o preparación como ejemplares científicos para el estudio, es lógico que puedan presentar una acidificación importante. Finalmente, su almacenamiento con materiales como maderas, adhesivos, chapas, resinas, papeles o cartones, pueden contribuir a generar una perjudicial acidificación, tanto en los ejemplares y soportes, como en el ambiente del almacén. El resultado es un conjunto de factores combinados que requieren un estudio singular de las condiciones de conservación, donde los paramétros ambientales adquieren un protagonismo indiscutible dadas las posibles reacciones químicas que pueden ocurrir debido a la interacción de los materiales entre sí o con el medio que les rodea.

Este deterioro ya fue diagnosticado con anterioridad, cuando en 1984 se sustituyeron los antiguos muebles y estanterías de madera por armarios y bandejas metálicas. Con esta actuación se prevenía la emanación de compuestos ácidos, como el ácido acético, dentro del ambiente del almacén por parte del mobiliario.

Sin embargo, todavía conservan materiales históricos, de relleno o empleados como soportes auxiliares, que presentan acidificación, como los algodones y la paja [Figura 1], llegando a alcanzar unos valores de pH de 4 unidades.

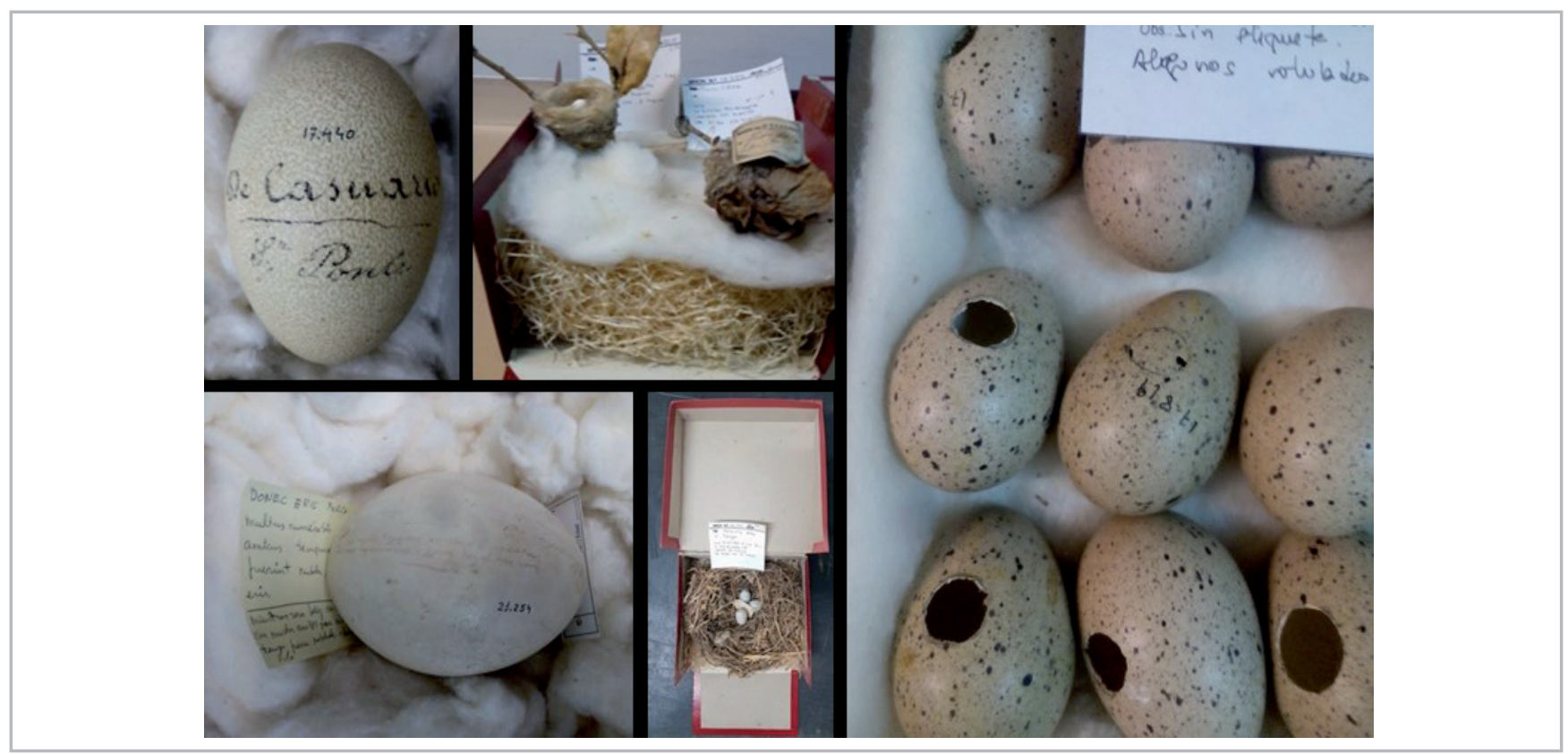

Figura 1.- Ejemplares en los almacenes de la colección de Oología del MNCN con algodón y paja como soporte. Imagen: @Luis Castelo 
Estos elementos poseen una elevada higroscopicidad, con gran capacidad para absorber los compuestos ácidos orgánicos del entorno, que migran con gran facilidad a sus estructuras porosas vegetales desde un ambiente ácido o por contacto. El fuerte olor a naftalina que desprenden los más antiguos al mojarlos, su color o su textura, son otros datos organolépticos (Galán 2014) a tener en cuenta, dado que algunos ejemplares de las colecciones de estudio conservan el algodón y la paja originales del siglo XIX.

El objetivo de la investigación ha sido encontrar una opción diferente al algodón y a la paja como materiales de soporte y relleno dada la evidente degradación que presentan, utilizando productos sintéticos inertes y estables alternativos, como la poliamida 6 (PA6), también conocida como Nylon ${ }^{\circledR} 6$ o Perlón ${ }^{\circledR}$ (Porcel \& Artetxe 2016). Este material, empleado en múltiples ámbitos de la arquitectura o la industria, posee unas cualidades que lo hacen idóneo para los fines que se buscaban, a tenor de los resultados obtenidos en las pruebas de resistencia a diversos factores de deterioro a los que ha sido sometido.

\section{Metodología y resultados}

Los contaminantes de origen externo más importantes que se pueden encontrar son el dióxido de azufre $\left(\mathrm{SO}_{2}\right)$, los óxidos de nitrógeno $\left(\mathrm{NO}_{\mathrm{x}}\right)$, el ozono $\left(\mathrm{O}_{3}\right)$ y el sulfuro de hidrógeno $\left(\mathrm{H}_{2} \mathrm{~S}\right)$ (García; Villegas 2015), mientras que los contaminantes ácidos producidos por materiales dentro de las propias estancias son el ácido acético $\left(\mathrm{CH}_{3} \mathrm{COOH}\right)$ y el ácido fórmico (HCOOH) (Palomar 2017: 58-60). Estos compuestos orgánicos volátiles (VOC) causan graves deterioros tanto a materiales orgánicos como inorgánicos y son emitidos por maderas, siliconas, adhesivos, etc. En este caso en particular, hay que tener en cuenta, además, los materiales constitutivos de las propias colecciones y las sustancias acidificantes utilizadas para su preparación y conservación, como el ácido sulfúrico (Aragón 2005: 3238).

La primera fase de trabajo se ha basado en el estudio de la contaminación ambiental del almacén C-12: acidificación ambiental, cálculo de compuestos orgánicos volátiles totales, formaldehído, ácido acético y fórmico; y en la segunda fase se han llevado a cabo las pruebas de acidificación en soportes de algodón no graso y paja mediante la determinación del pH en fragmentos sólidos.

La medición de la acidificación se ha realizado in situ, con el empleo de equipos portátiles para evitar, en la medida de lo posible, el traslado de las piezas a los laboratorios de análisis. Tras los ensayos preliminares de acidificación, se ha incorporado como medida de conservación preventiva, e incluida dentro de las actuaciones que se han realizado en el marco del Proyecto HAR2017-82894-P (MCIU-AEl/ FEDER, UE) reflejadas en este artículo, papel secante libre de ácidos, sobre las bandejas de metal de la Colección de Oología, principal colección con soportes de algodón y paja del almacén [Figura 3a]. Finalmente, se han realizado pruebas de envejecimiento acelerado de varias muestras del material propuesto como sustituto del algodón y la paja, tanto en soportes como en relleno de ejemplares, para comprobar su idoneidad para el fin requerido.

\section{- El pH ambiental del almacén C-12}

Este sistema constituye una herramienta importante en la toma de decisiones para el personal encargado de la conservación de este tipo de colecciones o de proponer planes de conservación preventiva a largo plazo. Entre las técnicas más utilizadas actualmente para medir la acidificación ambiental -como las probetas metálicas, captadores pasivos, sensores ópticos de acidez ambiental y microextracción en fase sólida (SPME)- se ha optado por los sensores ópticos [Figura 2a]. Estos sensores de pH ambiental, basados en la tecnología Sol-gel, permiten determinar el $\mathrm{pH}$ en el aire con una precisión de $\pm 0,1$ unidades de la escala de $\mathrm{pH}$ (Peña et al. 2015: 14-26). Se utilizan con un dispositivo electrónico portátil de medida in situ, según patente $O P M$, n²01031071 (García; Villegas 2015).

Los sensores ópticos están formados por una capa de vidrio poroso realizado con la tecnología Sol-gel, depositada sobre un portamuestras de vidrio de microscopía. La especie química utilizada como fase sensora es el rojo de clorofenol, un colorante orgánico. Este se incorpora a la red vítrea de sílice pura de un grosor aproximado de $300 \mathrm{~nm}$, ocupando los poros más externos de la red por adsorción; así puede el rojo de clorofenol entrar en contacto con las especies ácidas del ambiente. Los sensores no son específicos para determinar ningún ácido concreto sino para determinar todos los compuestos acidificantes o alcalinos totales que se encuentran en el ambiente a medir (Peña 2014: 34-35).

Se han utilizado ocho sensores dentro del almacén C-12. Los datos obtenidos de $\mathrm{pH}$ ambiental, cercanos a la neutralidad, se han conseguido haciendo mediciones cada 24 horas, durante cuatro días consecutivos [Gráfico 1]. Los resultados conseguidos reflejan, por un lado, la efectiva respuesta de los sensores ante los cambios producidos en el entorno, como las consecuencias de las visitas en la estabilidad de las condiciones ambientales, con los presumibles cambios de temperatura y humedad relativa en las diferentes estancias del almacén que afectan al pH; siendo el habitáculo donde se situó sensor n 6 el menos visitado $y$, por lo tanto, el que conserva unas condiciones más estables.

\section{- Compuestos orgánicos volátiles totales y formaldehído}

Los compuestos orgánicos volátiles son compuestos químicos con carbono que suelen encontrarse en forma de gas. Los más comunes que se pueden generar en el interior, y poner en peligro el patrimonio de los museos, son entre 
otros, el ácido acético, el ácido fórmico y el formaldehído (Grzywacz 2006). Este último se suele encontrar asociado a materiales contrachapados que emiten un olor muy característico, presentes en la fabricación de muchos objetos cotidianos. De igual manera las emanaciones de ácido acético y fórmico son muy comunes en materiales con composición orgánica como algunas maderas. Los museos de Historia Natural, sus colecciones y mobiliario pueden ser una fuente de emisión de estos compuestos.
Para detectarlos se ha empleado el medidor de $\mathrm{HCHO} /$ TVOC PCE-VOC 1, instrumental de muy fácil manejo que determina los VOCs [Gráfico 2] y el formaldehído en ppm y $\mathrm{mg} / \mathrm{m}^{3}$ [Gráfico 3]. Se han realizado para este ensayo, cinco mediciones en cada uno de los siete habitáculos del almacén C-12 del Museo, incluyendo el pasillo interior del mismo. Los resultados expuestos, en los dos gráficos y sus tablas, son producto de la obtención del promedio de los cinco datos de cada sección aislada con puerta.

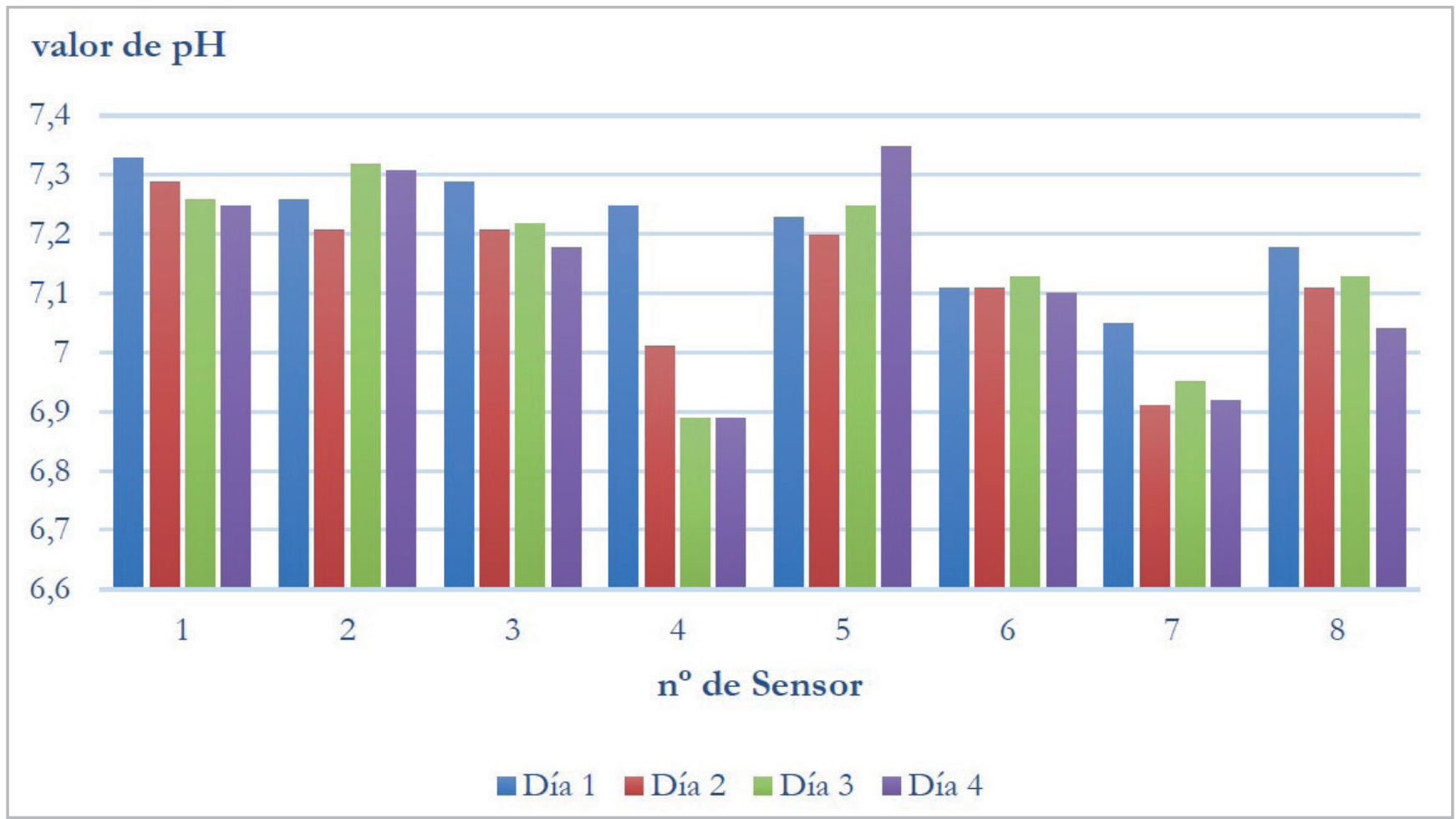

Gráfico 1.- Datos de pH obtenidos en cuatro días consecutivos a través del software del equipo portátil. Elaboración propia.

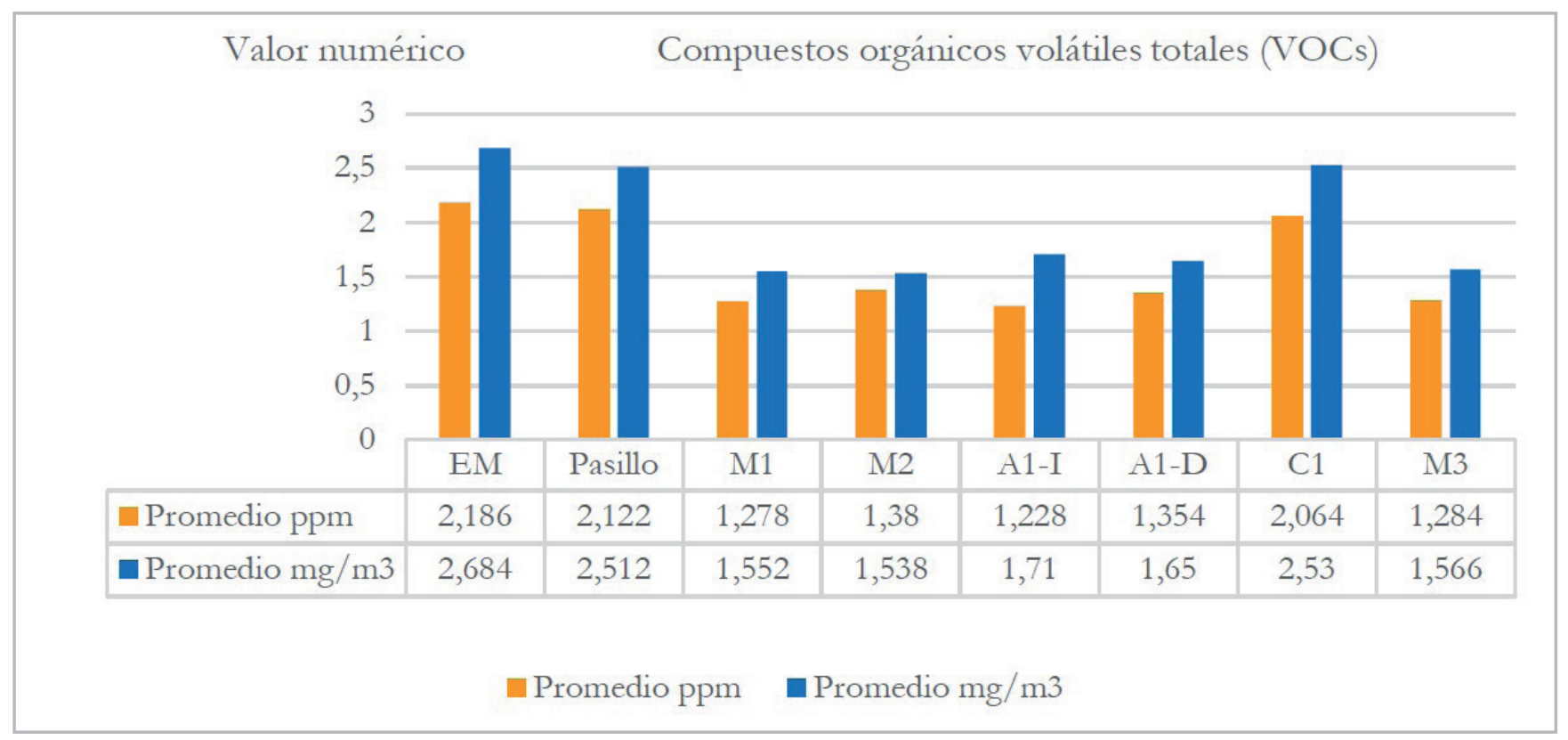

Gráfico 2.- Promedio de VOCs. Elaboración propia. 


\section{Valor numérico de $\mathrm{HCHO}$ (formaldehído)}

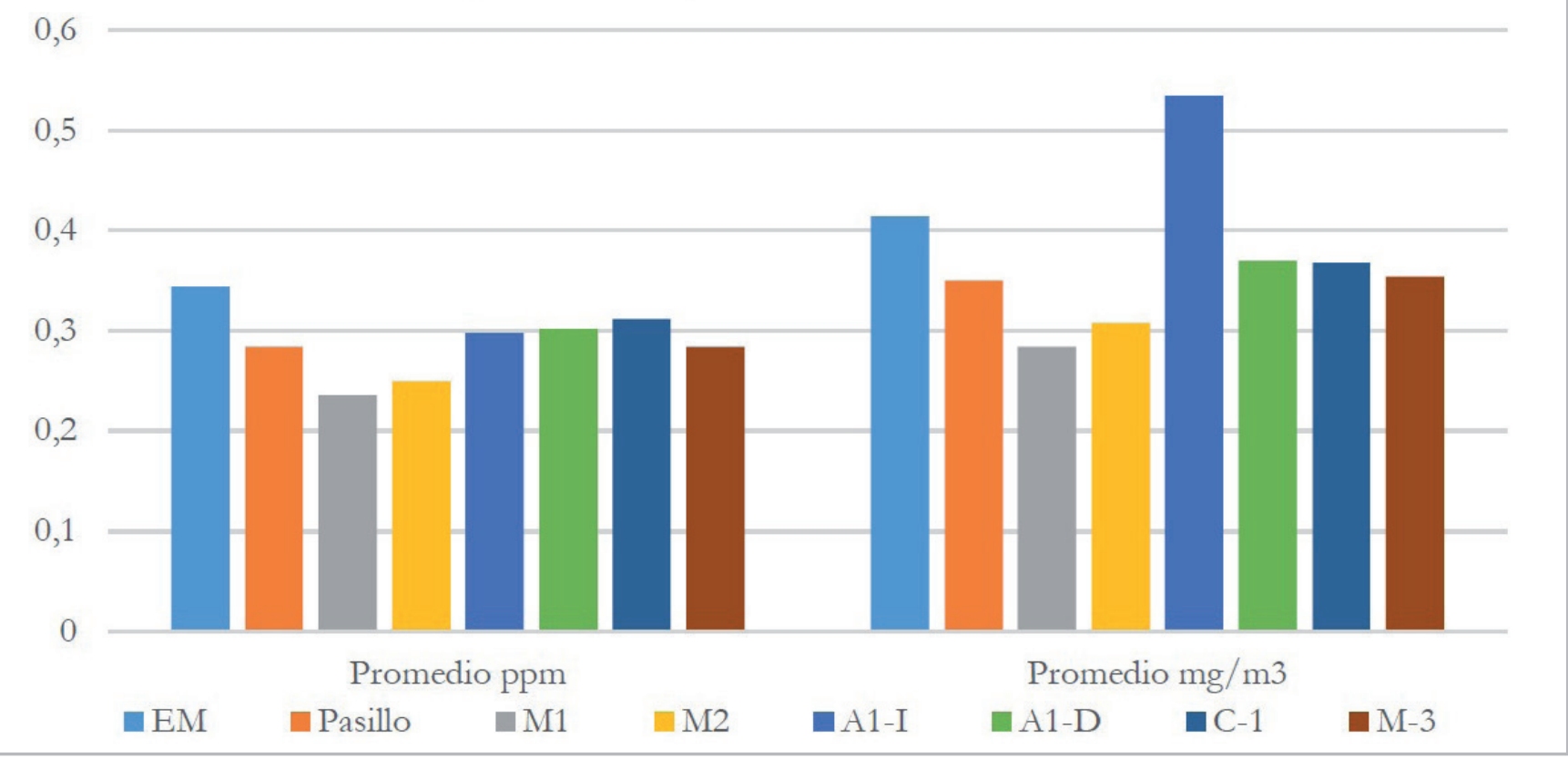

Gráfico 3.- Promedios de las concentraciones de formaldehído en el almacén C-12. Elaboración propia

El promedio obtenido es el resultado de las mediciones realizadas cada 24 horas durante cinco días en los diferentes habitáculos del almacén. El de mayor volumen (A1), donde se conserva la Colección de Aves, tiene un formato rectangular muy largo (12 m). Por ello se colocaron dos sensores en sus extremos derecho e izquierdo (A1-I y A1-D), siendo el acceso al mismo por la zona central. En el momento de realizar los ensayos, sólo el habitáculo de la Colección de Aves y los de la Colección Mamíferos M1, M2 y $M 3$, disponían de sistema refrigeración específica para este tipo de colecciones en almacén $\left(16^{\circ} \mathrm{C}\right)$, paramétrica ya solucionada en la actualidad; por lo que probablemente, los resultados reflejados en el gráfico n 2 , más elevados, corresponden al habitáculo con mamíferos (EM), situado junto a la puerta de entrada al almacén; a los de la cámara C1 y a los del pasillo central que comunica con todas las dependencias mencionadas. Por otra parte, en los resultados del gráfico $n^{\circ} 3$ se evidencia el aislamiento de la Cámara C1, mayormente reflejado por el equipo portátil en $\mathrm{mg} / \mathrm{m}^{3}$ que en ppm del resto de las estancias; así como los diferentes registros en las dos zonas del habitáculo de las aves, posiblemente motivados por un agrupamiento de un determinado número de especies con unos particulares métodos de conservación. De todos modos, se debe tomar con reservas, la exactitud de los resultados preliminares en mediciones de contaminantes con equipos portátiles de amplio espectro.

\section{- Mediciones de ácido acético y fórmico en ambiente}

Para la determinación de ácido acético y fórmico en bibliotecas y archivos, Tacón Clavaín (2008:71) propone una versión de la SPME (Solid Phase Microextraction) que no necesita su posterior análisis en laboratorio con técnicas analíticas de cromatografía de gases y espectrómetro de masas (GC/MS). Se trata de unos tubos colorimétricos, llamados "de rango corto", utilizados con una pequeña bomba manual. Para determinar cada compuesto químico existe un tubo específico que se acopla a la bomba [Figura $2 b]$, una vez cortado por ambos lados y ejerciendo un número determinado de presiones manuales para cada compuesto. Para el ácido acético hay que presionar 3 veces la bomba y para el fórmico, 20. La información facilitada por el fabricante respecto a la sustancia indicadora utilizada es:

\section{$\mathrm{HCOOH}+$ indicador $\mathrm{pH} \longrightarrow$ producto de reacción amarillo}

Las medidas en ppm se observan directamente en los tubos de vidrio por el cambio de color del producto en su interior [Figura 2c]. En los de ácido acético el rango de medidas se expresa de cinco en cinco unidades, por lo que resulta más difícil de cuantificar que en los de ácido fórmico.

El ácido fórmico y el acético se forman por la oxidación del formaldehídoy el acetaldehído respectivamente, por lo que se consideran primarios a los aldehídos y contaminantes secundarios a los dos ácidos. Las concentraciones más bajas de estos ácidos contaminantes se han detectado en zonas ventiladas y con movimiento, estando las concentraciones más altas en lugares y almacenes con poca ventilación y pocas visitas. Aunque no existe un estándar de condiciones ambientales de tomas de muestras para determinar acidificación ambiental con estos detectores, las medias tomadas en el almacén C-12 con los tubos Dräger ${ }^{\circledast}$ presentan resultados muy llamativos [Tabla 1] dado que las concentraciones de fórmico provenientes de la madera 


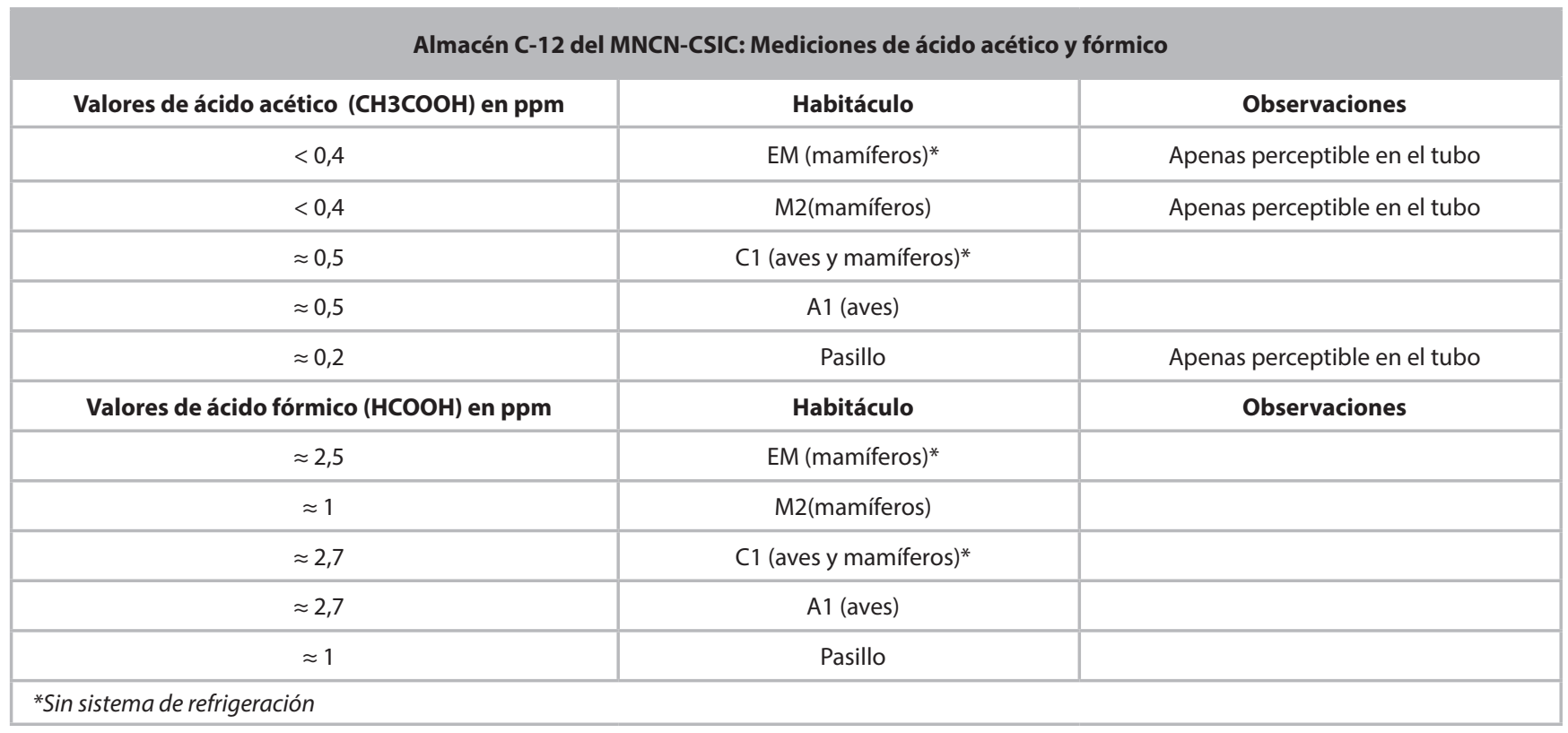

Tabla 1.- Datos obtenidos con los tubos de rango corto Dräger ${ }^{\circledR}$. Elaboración propia.

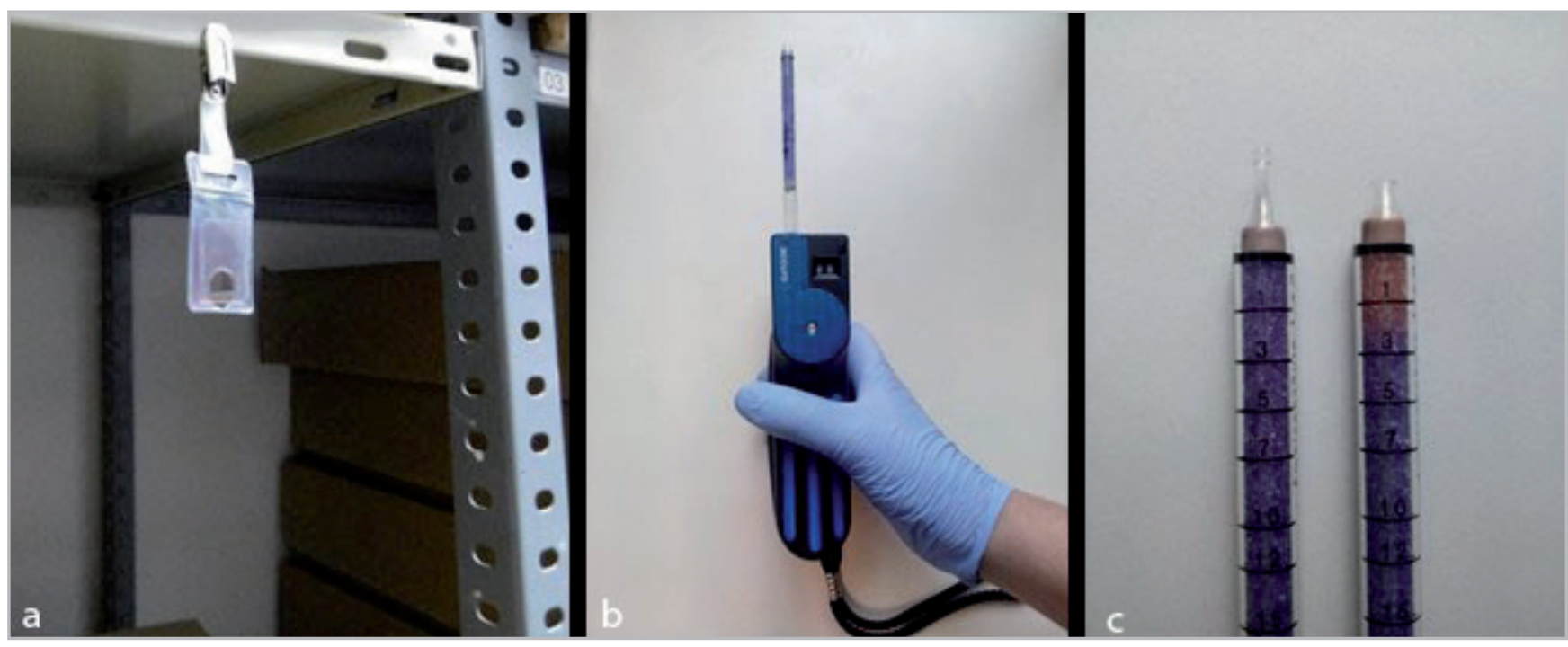

Figura 2.- a) Sensor Sol-gel instalado en el almacén C-12; b) Bomba y tubo de rango corto listos para su uso; c) Cambio de color apreciado en el tubo derecho tras la medición. Imágenes: @Óscar Ramos-Lugo.

son inferiores que las procedentes del acético (Gibson 2010: 172-178; Krupińska et al. 2013: 350-360). Estos datos pueden indicar un origen diferente de las concentraciones de fórmico de dicho almacén. La presencia de peróxido de hidrógeno $\left(\mathrm{H}_{2} \mathrm{O}_{2}\right)$ podría tener alguna relación en la oxidación del formaldehído hacia el ácido fórmico, dado que este producto se ha utilizado en la preparación de colecciones de Historia Natural para su conservación, sobre todo en la limpieza de colecciones de huesos y esqueletos.

\section{Pruebas de indicios de acidificación en soportes}

Los primeros ensayos de acidificación tienen como objetivo servir de apoyo al examen organoléptico y, a partir de los resultados obtenidos, realizar pruebas más exactas en los materiales seleccionados a partir de los mismos. Se ha elegido el uso de la goma xantana y los lápices indicadores para las mediciones previas de $\mathrm{pH}$ en los soportes orgánicos de las colecciones del almacén de estudio.

Los soportes orgánicos históricos de las colecciones del almacén C-12 son principalmente el algodón (graso y sin tratar), el papel, la paja y las cajas de cartón. Todos ellos presentan una gran variedad de procesos de fabricación, dado el tiempo que se llevan utilizando y las diferentes calidades empleadas para proteger las colecciones. En algunos casos, al tratarse de técnicos colectores de especies silvestres, se empleó el material que se tenía a mano, como un papel de periódico, ya igualmente histórico, para transportarlas y preservarlas en cajas, igualmente antiguas. 
El uso de lápices indicadores de $\mathrm{pH}$, se presenta como un método de contacto preliminar rápido y sencillo aplicable en algunas superficies sólidas. Están provistos de indicadores químicos como el clorofenol, el indicador se vuelve lila en una superficie marcada que tenga un $\mathrm{pH}$ superior a 6,8 y amarilla si la superficie de los materiales es ácida. Un tono tostado indicará cierta neutralidad. La superficie a teñir es mínima dado que se trata de aplicar una simple y pequeña línea $y$, por lo tanto, el perjuicio es menor. Existen varias marcas disponibles en el mercado como el $p H$ Abbey pen ${ }^{\circledR}$, el de Hidrion ${ }^{\circledR}$ o el LINECO $p H$ testing pen ${ }^{\circledast}$ utilizado en estos ensayos.

Actualmente, el uso de geles, como el de agarosa o el gellano, para la limpieza de materiales de Patrimonio Histórico está muy generalizado (Wolbers 2013). La aplicación de la goma xantana, comercializada también con el nombre de Vanzan NF-C ${ }^{\circledR}$, puede ser factible como medio preliminar para determinar el $\mathrm{pH}$ de materiales sólidos dada la estabilidad de este polisacárido en emulsiones con un rango de $\mathrm{pH}$ muy amplio; característica principal para su uso en muchos campos de investigación (Palaniraj \& Jayaraman 2011: 1-12) como la alimentación; así como su viscosidad, la cual se mantiene en rangos de concentración bajos, lo que la convierte en un producto de fácil aplicación. Este biopolímero $\left(\mathrm{C}_{35} \mathrm{H}_{49} \mathrm{O}_{29}\right) n$ es soluble en agua y parcialmente insoluble en disolventes orgánicos. Su viscosidad está condicionada por la temperatura, por lo que es recomendable su uso a temperaturas no elevadas, sobre todo si se pretende su uso como técnica no destructiva, evitando manchar el material, sobre todo el poroso.

Rebeca Pavitt (2012), en el IIC (The International Institute for Conservation of Historic and Artistic Works), recomienda para los tratamientos de limpieza en superficies con pigmentos, utilizar el gel rígido de agarosa para materiales que no deben ser mojados y el de goma xantana para papeles y textiles que se puedan lavar. La ventaja en mediciones puntuales in-situ radica en que la goma xantana no necesita ser calentada para prepararla, a diferencia del gel de agarosa; aunque se tarde unos 15 minutos en hacerlo homogéneo. De todas formas, una aplicación del gel de goma xantana de forma precisa y en zonas no visibles, puede dejar una pequeña marca eliminable haciendo uso de etanol diluido aplicado con un hisopo en el momento de la retirada del gel, si la muestra lo admite previa cata, o con agua desionizada en su defecto. Al ser soluble en agua, su preparación es muy sencilla y su rango de concentración puede situarse en torno al 2\%, para los fines propuestos de $\mathrm{pH}$, una concentración superior a la empleada en la industria, la cual ronda entre el 0,1 y el $1 \%$. La goma xantana alimentaria (E-415) se prepara en frío con $100 \mathrm{ml}$ de agua destilada o desionizada a la que se le puede añadir un conservante: phenonip al 0,5\%. Lo ideal, aunque sea un producto muy estable, es preparar el gel en frío. Una vez homogeneizado el gel se coloca una pequeña cantidad sobre la muestra [figura $3 \mathrm{~b}$ ] y pasados 30 minutos aproximadamente, se introduce una tira indicadora de $\mathrm{pH}$ dentro del gel, para determinar su valor. Dado el alto porcentaje de agua que contiene el gel, se produce la migración de los compuestos ácidos al mismo detectados por las tiras indicadoras que reaccionan con un cambio de color contrastable. Con esta técnica, al no ser exacta, es recomendable aumentar su fiabilidad utilizando tiras con una escala estrecha de $\mathrm{pH}$, por ejemplo, entre 3 y 6 , si hay sospechas de cierto grado de acidez en las muestras.

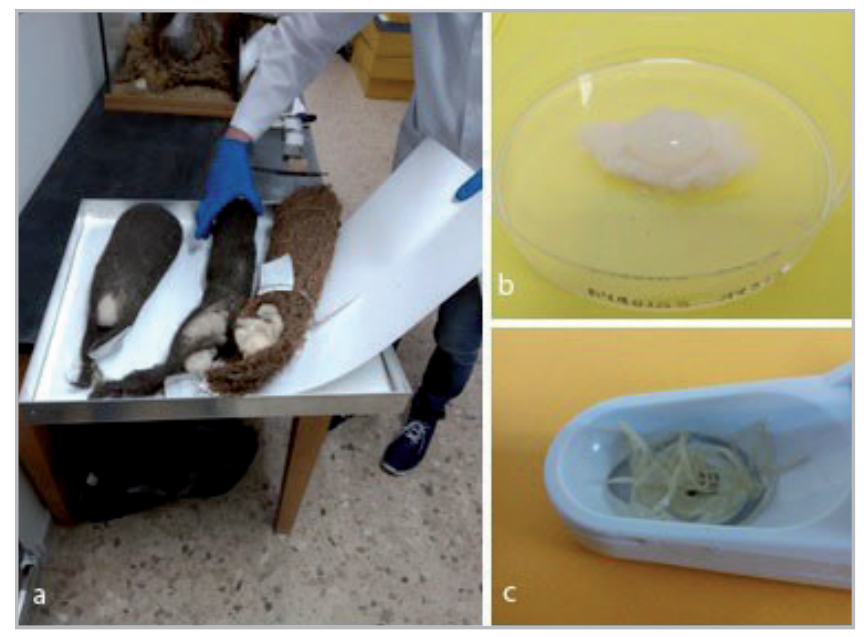

Figura 3.- a) Colocación de papel secante libre de ácidos en una bandeja de la Colección de Oología; b) Ensayos preliminares de acidificación en soportes con el uso de gel de goma xantana; c) Determinación de $\mathrm{pH}$ de una muestra de paja con el LAQUAtwin $\mathrm{pH}$ 33®. Imágenes: ๑Óscar Ramos-Lugo.

\section{- El pH de soportes sólidos humectados con equipos portátiles}

Un método directo que se utilizó para determinar el pH de los soportes históricos en las colecciones del almacén C-12 del MNCN fue un equipo portátil manual LAQUAtwin $\mathrm{pH}-33^{\circledR}$ de HORIBA [Figura 3c], adecuado dada su facilidad de uso y la posibilidad de analizar muestras sólidas humectadas, líquidas y semisólidas, gracias a una variación de la técnica del electrodo de vidrio en electrodo plano. Este pequeño equipo portátil permite analizar las pequeñas muestras sólidas con unas gotas de agua desionizada, por lo que se trata de una técnica mínimamente destructiva.

Otro de los instrumentos empleados con este mismo fin ha sido el testo $206 \mathrm{pH} 2^{\circledR}$, que incorpora a la sonda de inserción de vidrio, otra de temperatura integrada, aunque independiente; muy adecuada para este tipo de medidas dada la influencia de la temperatura en la viscosidad de muchos preparados analizados. El equipo es estanco y las sondas son muy robustas, por lo que apenas necesita mantenimiento, sólo una sencilla calibración y aclarado con agua y paño suave.

Los dos gráficos siguientes [Gráficos 4 y 5] muestran los datos de mediciones de $\mathrm{pH}$ de cuatro muestras de algodón no graso y paja históricos respectivamente, analizados con ambos determinadores de $\mathrm{pH}$ portátiles. Estos dos materiales se encuentran actuando de soporte de 
ejemplares de Oología o como elementos estructurales en el interior de ejemplares de taxidermia.

Los gráficos muestran los resultados de las determinaciones de $\mathrm{pH}$ en materiales, realizadas siguiendo un método de ensayo del Canadian Conservation Institute (TB 28) utilizando el testo $206 \mathrm{pH} 2^{\circledR}$. Con esta técnica mínimamente destructiva se han tomado, según el método, 0,25 g de muestra sólida sumergida en $12,5 \mathrm{ml}$ de agua desionizada durante una hora. Con el LAQUAtwin $\mathrm{pH}-33^{\circledR}$ se ha utilizado una pequeña cantidad sin determinar para introducirla en el mismo con unas gotas de agua desionizada, por lo que este último método es también mínimamente destructivo
[Figura 3c]. Los algodones y paja históricos utilizados como soportes de conservación muestran un pH muy bajo. Se realizaron, en el caso del algodón, con muestras no grasas dado que los tratados con aceites son excesivamente hidrófobos y no aptos para estos ensayos. Los distintos valores obtenidos en las diferentes muestras, mostrados en las gráficas 4 y 5, pueden ser el reflejo de distintas calidades de los materiales, así como de contaminantes presentes en el ambiente e insecticidas que han sido empleados a largo de décadas para su conservación, evitando la degradación y pérdida de ejemplares por la acción de los temidos derméstidos en colecciones de taxidermia. En el caso de las muestras de paja analizadas, la comparativa

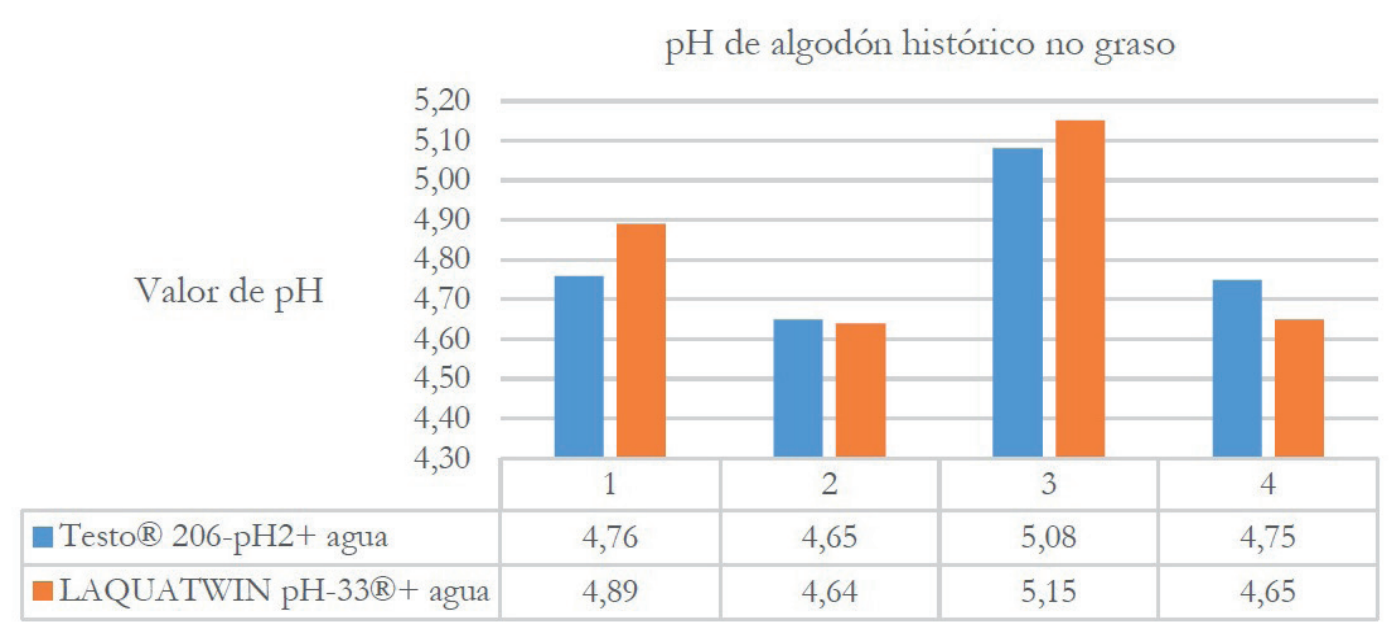

-Testo® 206-pH2+ agua —LAQUATWIN pH-33®+ agua

Gráfico 4.- Medidas de pH en cuatro muestras de algodón histórico. Elaboración propia.

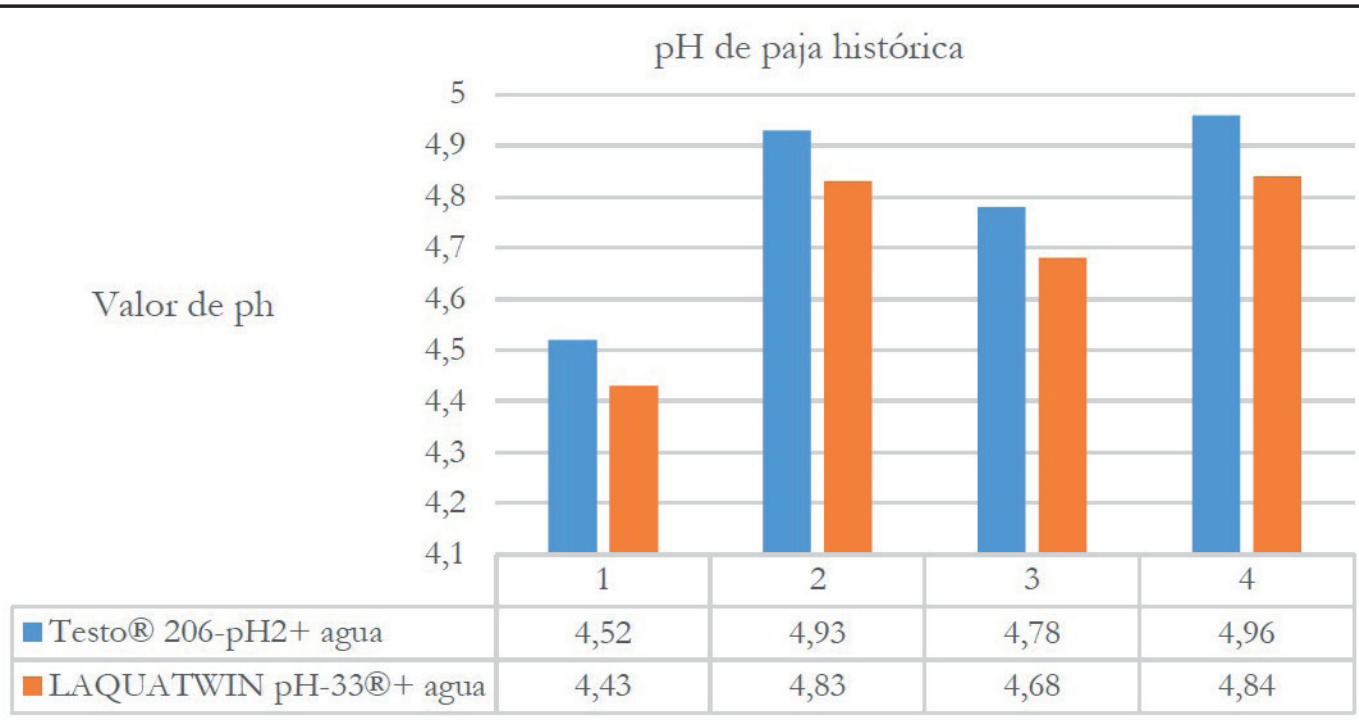

Testo® 206-pH2+ agua $\quad$ LAQUATWIN pH-33®+ agua

Gráfico 5.-Medidas de pH en cuatro muestras de paja histórica. Elaboración propia. 
de los resultados entre los dos equipos refleja una cierta proporción que no se evidencia en el algodón. Con las reservas ante los datos aportados, se puede evidenciar una mayor estabilidad del material en las muestras de paja, en las mismas condiciones ambientales del ensayo en ambos materiales con los dos equipos. De todas formas, se evidencia una acidez incuestionable en ambos, aunque uno pudiera ser más higroscópico que el otro y retener mayor cantidad de compuestos ácidos.

\section{Propuesta alternativa a los soportes orgánicos}

Durante la realización de los ensayos en este trabajo se ha buscado una opción diferente al algodón y la paja como material de soporte y relleno para las Colecciones Históricas, con el objetivo de proponer otros productos inertes y estables alternativos a estos dos, que no sean orgánicos, dada la evidente degradación que sufren y padecerán estos últimos por su utilización, tanto como soporte en almacenes, como elementos internos estructurales.

Se han realizado ensayos con material filtrante para acuarios, ya que la filtración es básica en un acuario para mantener las condiciones adecuadas requeridas por las especies animales y vegetales que contiene valores inadecuados en los parámetros físico-químicos del agua, que causan la mayor parte de los problemas de salud en peces en cautividad (Garvía 2017). Así, la influencia de los materiales utilizados en el sistema de filtración de instalaciones acuáticas debe ser necesariamente conocida antes de su uso. Aunque en determinadas ocasiones se emplean materiales específicos precisamente para modificar el $\mathrm{pH}$, como por ejemplo la turba, en general lo que se le exige a un material para este fin es que no modifique el $\mathrm{pH}$ del agua y únicamente actué como filtrante inerte en cuanto a los principales parámetros físico-químicos del agua, incluido el pH. Grandes fluctuaciones en este parámetro en el agua implican alteraciones fisiológicas y de salud en los peces y otros organismos acuáticos.

En concreto, se ha determinado el pH de una fibra sintética usada comúnmente en la filtración mecánica del agua de las peceras: el Perlón ${ }^{\circledast}$. Los ensayos de pH con este material, utilizando el testo $206 \mathrm{pH} 2^{\circledR}$ y el LAQUAtwin $\mathrm{pH}$ $33^{\circledR}$, han dado como resultado los valores del $\mathrm{pH}$ del agua desionizada utilizada para hacer los ensayos. Un resultado lógico y muy positivo dado que esta fibra debe ser inerte y estable. Un cambio en el $\mathrm{pH}$ del agua motivado por un material susceptible de degradación podría resultar fatal para las especies del acuario. Este argumento de peso, unido a los ensayos de $\mathrm{pH}$, a la plasticidad del material y a su reversibilidad, justifica la opción de servir como sustituto a la paja y el algodón como materiales de relleno en ejemplares de historia natural. El Perlón ${ }^{\circledR}$ es un material inerte utilizado para la purificación mecánica, que se encuentra dentro de la categoría de fibras sintéticas. Conocido por sus diferentes espesores como perlón, guata, esponja o lana de perlón [figura 4a], es un polímero sintético de poliamida (PA) cuyas propiedades son entre otras, elasticidad, resistencia mecánica, plasticidad, rigidez media y fácil manejo.

Seguidamente a los ensayos de $\mathrm{pH}$ se han sometido cuatro muestras comerciales de Perlón ${ }^{\circledR}$ a ensayos de envejecimiento con radiación solar, alta temperatura y baja humedad relativa durante 28 días, dado que experimentos previos de menos de 28 días no produjeron resultados. Las pruebas han sido realizadas en el Laboratorio de Ensayos Ambientales LEA/LET del MNCN-CSIC con una cámara climática MQ/ESP [Figura 4b] equipada con Función Radiación Solar mediante lámparas de espectro radiante (radiación UV, visible e infrarroja próxima) similar al emitido por el sol, basados en gases ionizables a alta presión en vidrio de cuarzo y por una espiral incandescente de wolframio, (energía media radiada de aprox. $800 \mathrm{~W} / \mathrm{m} 2$, con una potencia instalada de aprox. $5 \mathrm{KW} / \mathrm{m} 2$, sin filtros de vidrio de aislamiento) equivalente a la radiación registrada en el ecuador en el máximo de intensidad solar (al mediodía). La potencia total instalada de radiación está formada por cuatro lámparas de $300 \mathrm{~W}$ cada una, totalizando $1200 \mathrm{~W}$ totales (LEA/LET @Museo Nacional de Ciencias Naturales: 2021). Se introdujeron en la cámara las cuatro muestras de las marcas comerciales adquiridas en contacto con ejemplares de Oología de prueba (sin valor patrimonial) y distintos soportes en contacto con el Perlón ${ }^{\circledast}$ : en cajas de cartón libres de ácidos con muestras y sin su tapa, para favorecer la radiación; Perlón ${ }^{\circledast}$ en cajas de poliestireno transparentes; Perlón ${ }^{\circledast}$ directamente en contacto sobre la bandeja metálica de la cámara y, finalmente, muestras sobre papel secante de conservación libre de ácidos sin reserva alcalina Multisorb $T M, 280^{\circledast}$ de g. libre de ácidos. Este papel se utilizó para cambiar los que se encontraban anteriormente colocados sobre las bandejas de la Colección de Oología, como medida preventiva de conservación, posterior a la realización de los ensayos de acidificación ambiental [Figura. 3a].

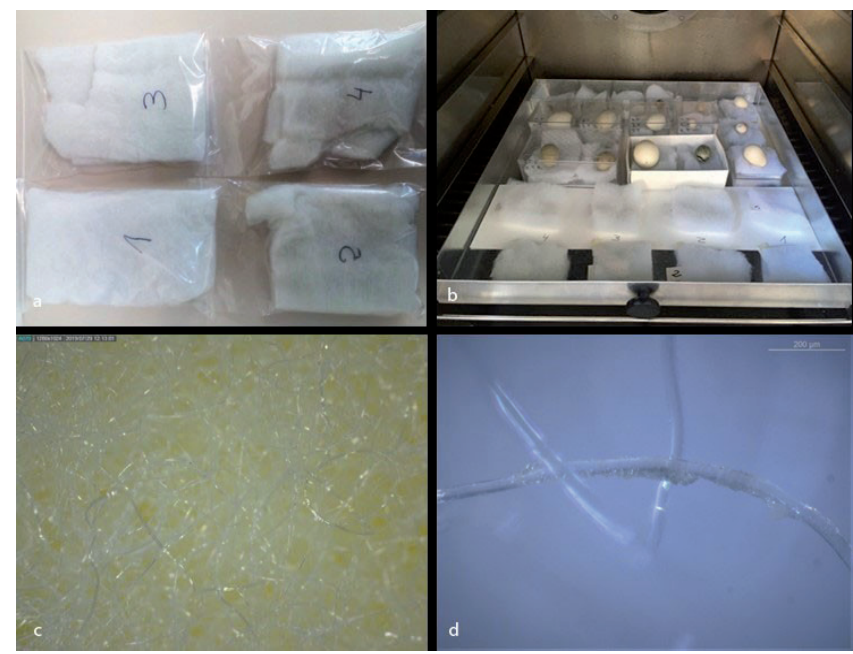

Figura 4.- Muestras de Perlón ${ }^{\oplus}$ : a) Las cuatro muestras comerciales para el ensayo; b) Muestras dentro de la cámara de envejecimiento; c) Imagen del Dino Capture 8x; d) Imagen del Leica ${ }^{\circledR}$ M205-A 200 $\mu \mathrm{m}$. Imágenes a y b: @Óscar Ramos-Lugo. 


\section{Conclusiones}

La interpretación de los valores de acidificación ambiental obtenidos evidencia el predominio del ácido fórmico frente al acético. Este dato resulta especialmente interesante teniendo en consideración que el lugar donde se han tomado las mediciones alberga colecciones de materia orgánica, fundamentalmente de origen animal. Los datos de VOCs totales y el formaldehído reflejan el grado de renovación del aire del almacén, así como de la cantidad de materiales usados en taxidermia. Sorprenden los niveles de neutralidad de $\mathrm{pH}$, cuya justificación podría hallarse en la existencia de una HR muy baja, característica de Madrid, la cual podría minimizar la acción, en estado latente, de los compuestos orgánicos presentes determinados con estos ensayos, sobre los soportes y ejemplares conservados en el almacén de estudio. La ventilación puede jugar asimismo un papel relevante en el mantenimiento de la neutralidad del pH ambiental, al permanecer estas colecciones aisladas de los parámetros externos medioambientales.

En los ensayos realizados con materiales empleados como soporte y/o relleno, los resultados muestran evidencias de acidificación, sobre todo en los más antiguos. Entre algodones no grasos nuevos y los históricos o antiguos, la diferencia puede superar los dos puntos de pH. La acidificación de los últimos es debida a su antigüedad $y$ al tipo de ambientes en los que han permanecido, donde han absorbido compuestos orgánicos, así como insecticidas, muy usados en otras épocas en las que no se conservaban las colecciones de historia natural, como se mantienen hoy en día en almacenes. Actualmente se evita superar el umbral de temperatura de $16^{\circ} \mathrm{C}$ para anular la proliferación de los coleópteros derméstidos, entre otras especies, tan perjudiciales para este tipo de colecciones.

En cuanto a las muestras de Perlón ${ }^{\oplus}$, de las cuatro muestras sometidas a un proceso de envejecimiento acelerado durante 28 días, sólo una de ellas mostró signos evidentes de deterioro, con una notable abrasión en la estructura y en la superficie de sus fibras, según la información aportada por las imágenes tomadas con el

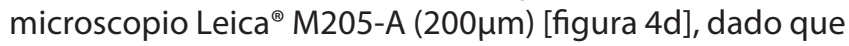
con la potencia del microscopio portátil USB Dino Capture $8 x$ [figura 4c] no se pudo apreciar dicho deterioro. Por lo tanto, se puede deducir que se trata de un material estable y apto para su uso como soporte. No obstante, a la hora de seleccionar una marca comercial es importante recurrir al origen de la producción, ya que existe la posibilidad de que algunos fabricantes incorporen determinados productos a las fibras para modificar sus propiedades con un fin específico. Tales añadidos, desde el enfoque de la conservación, podrían perjudicar su perdurabilidad en el tiempo, lo que imposibilitaría su uso como soporte. Por lo tanto, resulta necesario realizar ensayos de envejecimiento en este producto antes de su empleo, con el fin de contrastar su fiabilidad para el destino propuesto. Una vez verificada su idoneidad, estos nuevos materiales sintéticos se presentan como una alternativa viable y reversible con respecto a los algodones y la paja empleados en el pasado.

\section{Agradecimientos}

Proyecto HAR2017-82894-P (MCIU-AEI/FEDER, UE); cofinanciación de los ensayos por parte de la Vicedirección de Colecciones del MNCN: Josefina Barreiro (Colección de Aves) y Ángel Garvía (Colección de Mamíferos); personal del Instituto de Historia del CSIC: Ma A. Villegas, Javier Peña, Fernando Agua y Manuel García; Laboratorio de Ensayos Ambientales (LEA/LET) del MNCN-CSIC: Yolanda Fernández y Dolores Pesquero.

\section{Referencias}

ALMAGRO, M. (1866). Breve descripción de los viajes hechos en América por la Comisión Científica enviada por el Gobierno de S.M.C. durante los años de 1862 a 1866: acompañada de los mapas y de la enumeración de las colecciones que forman la exposición pública. Madrid: Ministerio de Fomento.

ARAGÓN, S. (2005). “La conservación de animales naturalizados de valor histórico", Revista Quercus, 228: 32-38.

BARREIRO, J; GARVÍA, A.; CASTELO, L. (2019). "La Colección de Aves", Las Colecciones del Museo Nacional de Ciencias Naturales: Investigación y Patrimonio. Madrid: Consejo Superior de Investigaciones Científicas, 235-252.

BARREIRO, J.; GONZÁLEZ, J. E.; REY, I. (1994). “Las colecciones de vertebrados: uso y gestión", Manual de catalogación y gestión de las colecciones científicas de Historia Natural. Manuales técnicos de Museología 1: 26-30, https://issuu.com/solemilia/docs/vol-01 catalogaciongestioncolecciones [consulta 15 enero 2021]

GALÁN, A.M. (2014). “El examen científico para la Conservación y Restauración de Patrimonio Histórico Educativo: el análisis organoléptico", Cabás 12: 38-48. http://revista.muesca.es/ articulos12/318-el-examen-cientifico-para-la-conservacion-yrestauracion-de-patri-monio-historico-educa-tivo-el-analisisorganoleptico [consulta 16 enero 2021]

GARCÍA, M; VILLEGAS, M. A. (2015). "Innovación y gestión de la conservación preventiva en museos: un ejemplo con colecciones de vidrio y materiales cerámicos". PH INVESTIGACIÓN, http://www. iaph.es/phinvestigacion/index.php/phinvestigacion/article/ view/89 [consulta 16 enero 2021]

GARVÍA, A. (2017). "Patologías Peces de Acuario: Casos Prácticos". $3^{\circ}$ Curso Aragonés de Gestión y Mantenimiento de Especies en un Acuario Público, Nivel I.

GIBSON, L. T. (2010). "Acetic and formic acids emitted from wood samples and their effect on selected materials in museum environments" Corrosion Science, 52 (1): 172-178. https://doi. org/10.1016/j.corsci.2009.08.054 
GRZYWACZ, C. M. (2006). "Monitoring for Gaseous Pollutants in Museum Environments". Tools for Conservation. Los Angeles, CA: Getty Conservation Institute. http://www.getty.edu/conservation/ publications resources/pdf publications/monitoring gaseous. html [consulta 16 enero 2021]

KRUPIŃSKA B., VAN GRIEKEN R., DE WAEL, K., (2013). "Air quality monitoring in a museum for preventive conservation: Results of a three-year study in the Plantin-Moretus Museum in Antwerp, Belgium", Microchemical Journal Volume 110: 350-360. https://doi. org/10.1016/j.microc.2013.05.006

MUSEO NACIONAL DE CIENCIAS NATURALES (LEA/LET) (2021). Laboratorio de Ensayos Ambientales. https://www.mncn.csic. es/docs/repositorio//es ES//investigacion/Servicios/Lab Tafonomia/laboratorio ensayos tafonomicos es.pdf [consulta 14 enero 2021]

PALANIRAJ, A; JAYARAMAN, V. (2011). "Production, recovery and applications of xanthan gum by Xanthomonas campestris", Journal of Food Engineering 106: 1-12, https://doi.org/10.1016/j. joodeng.2011.03.035

PALOMAR, T. (2017). “ ¿Y si tememos un ambiente ácido en el museo?", Revista MoleQla 25: 58-60. https://www.upo.es/cms1/ export/sites/upo/moleqla/documentos/Numero25/destacado 3. pdf [consulta 16 enero 2021]

PEÑA, J. (2014). Optimización, comportamiento y preindustrialización de sensores ambientales basados en la tecnología sol-gel. Tesis doctoral en Ciencias Químicas, Universidad Autónoma de Madrid Facultad de Ciencias, https://repositorio.uam.es/handle/10486/664117 [consulta 16 enero 2021]

PEÑA POZA, J.; GÁLVEZ FARFÁN, J. M.; GONZÁLEZ RODRIGO, M.; GARCÍA RAMÍREZ S.; VILLEGAS BRONCANO, M. Á. \& GARCIA HERAS, M. (2015). "Propuesta de protocolo de valoración de la acidez ambiental en salas y vitrinas de la exposición temporal El último viaje de la fragata Mercedes. La razón frente al expolio (Museo Naval, Madrid)", Ge-conservación 8: 14-26, https://doi. org/10.37558/gec.v8i0.279

PORCEL, A. y ARTETXE, E. (2016). “Una introducción a los textiles artificiales en las colecciones de indumentaria del siglo XX y su conservación", Ge-conservación 9:31-34.https://doi.org/10.37558/ gec.v9i0.276

TACÓN CLAVAÍN, J (2008). La conservación en archivos y bibliotecas. Prevención y protección, Madrid: Ollero y Ramos, 71.

WOLBERS, R. (2013). "Gel Media in Aqueous Cleaning Methods on Paper", The Book and Paper Gathering, Welcome Institute, London, June 19th 2013, https://thebookandpapergathering. org/2013/11/08/gel-media-in-aqueous-cleaning-methods-onpaper-a-lecture-by-professor-richard-wolbers-university-ofdelaware-presented-at-the-wellcome-institute-Iondon-june19th-2013/ [consulta 16 enero 2021].

\section{Autor/es}

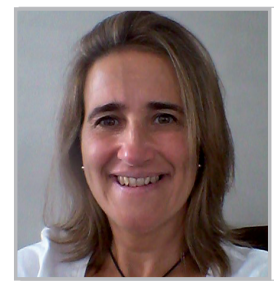

\section{Marta Plaza Beltrán}

mplazabe@art.ucm.es

Departamento de Pintura y ConservaciónRestauración de la Facultad de Bellas Artes (UCM, Madrid)

https://orcid.org/0000-0003-4545-6426

Doctora y Licenciada en Bellas Artes (UCM) en la especialidad de restauración. Profesora Titular del Departamento de Pintura y Conservación-Restauración de la Facultad de Bellas Artes (UCM). Su línea de investigación, académica y profesional se centra en la Conservación y Restauración del Patrimonio Cultural. Ha impartido docencia en diferentes titulaciones de Licenciatura, Grado y Máster, en la Universidad pública (UCM) y en la privada (Universidad SEK, IE University). Con estancias en centros docentes de Italia, Portugal, Taiwán, etc. Ha participado en numerosos proyectos de investigación y de docencia financiados, como directora y como miembro del equipo de investigación (I+D+I, art. 83, PIMCD). Igualmente, ha participado en importantes encuentros, seminarios y congresos. Posee publicaciones en revistas indexadas, así como monografías. Dentro del campo profesional ha sido responsable de la dirección técnica de obras de conservación-restauración en diferentes ámbitos: pintura mural, retablística, escultura, pintura de caballete, material etnográfico, etc. mediante contratación directa y concursos públicos a través de empresa propia (Sociedad Limitada). Ha trabajado para instituciones públicas y privadas (Patrimonio Nacional, Museos, Ministerios, Comunidades Autónomas, Diputaciones, Ayuntamientos, Embajadas, Obispados, Fundaciones, etc.). Ha elaborado informes técnicos específicos para concursos públicos y peritajes de conjuntos artísticos. Vinculado con la puesta en valor de conjuntos históricos destaca la realización de facsímiles de pinturas murales (gran formato). Miembro del comité científico y revisora de varias revistas especializadas. Revisora en dos editoriales, nacional e internacional. Evaluadora de la Agencia Estatal de Investigación (AEI).

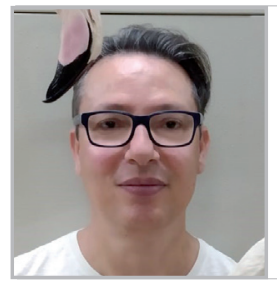

\section{Óscar Ramos-Lugo}

oramos01@ucm.es

Departamento de Pintura y ConservaciónRestauración de la Facultad de Bellas Artes (UCM, Madrid) https://orcid.orq/0000-0002-7595-3522

Historiador del Arte (UNED, 2014) especializado en conservación preventiva del Patrimonio Científico. Ha realizado tres másteres oficiales universitarios: Arqueología del Mediterráneo en la Antigüedad Clásica (UCM, 2015), Conservación del Patrimonio Cultural (UCM, 2016) y Diagnóstico del Estado de Conservación del Patrimonio Histórico (UPO, 2018). Diploma en Gestión, Conservación y Exhibición de Colecciones de Ciencias Naturales (UCM, 2017) y Técnico Superior de Laboratorio de Análisis y Control de Calidad (Instituto Politécnico de Las Palmas de Gran Canaria, 2006); ha participado en el Proyecto del Plan Nacional HAR2017-82894-P sobre condiciones de conservación 
de las Colecciones de Aves y Mamíferos del Museo Nacional de Ciencias Naturales (MNCN-CSIC). Trabaja actualmente en la Vicedirección de Exposiciones del MNCN-CSIC donde colabora en la divulgación del patrimonio de la institución a través de exposiciones y publicaciones en la revista digital del Museo. Realiza sus estudios de doctorado en la Facultad de Bellas Artes de la UCM sobre protocolos de conservación de colecciones artísticas de Patrimonio Científico y es miembro del equipo en el Proyecto INNOVA-Docencia (99-2020/2021) de esta Universidad.

Artículo enviado el 26/09/2021 Artículo aceptado el 07/10/2021

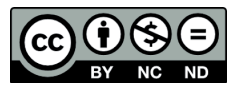

https://doi.org/10.37558/gec.v20i1.1060

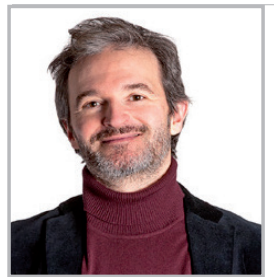

\section{Jorge Rivas López}

jrivaslo@art.ucm.es

Departamento de Pintura y ConservaciónRestauración de la Facultad de Bellas Artes (UCM, Madrid)

https://orcid.org/0000-0001-5238-9378

Doctor y Licenciado en Bellas Artes (UCM) con la Especialidad de Conservación y Restauración de Bienes Culturales. Máster en Gestión del Patrimonio Cultural (Título Propio UCM). Profesor Titular del Departamento de Pintura y Conservación-Restauración de la Facultad de Bellas Artes (UCM). Sus actividades académicas y profesionales han seguido una línea de actuación común: la conservación y restauración del Patrimonio Cultural. Ha desarrollado su labor docente en la universidad pública (UCM) y en la privada (Universidad SEK e I. E. University), impartiendo asignaturas pertenecientes a diferentes titulaciones: Grado en Conservación y Restauración del Patrimonio Cultural (UCM); Licenciatura de Bellas Artes (UCM); Licenciatura de Historia del Arte (Universidad SEK e I.E. University); Máster Universitarios UCM (Máster en Conservación del Patrimonio Cultural y Máster Universitario en Bienes Culturales, Conservación, Restauración y Exposición), así como en Títulos Propios de Posgrado (Magíster en Conservación y Restauración del Arte Contemporáneo UCM y Graduado Superior en Ciencias del Patrimonio de la Universidad SEK).

Ha formado parte del comité asesor y consejo de redacción de revistas indexadas con altos índices de impacto. Ha participado en calidad de Investigador principal de un Proyecto Competitivo Estatal de I+D+i de Excelencia (HAR2017-82894-P) y de miembro del equipo investigador en otro $\mathrm{I}+\mathrm{D}+\mathrm{i}$ del Programa Retos (HAR2009-10679). Dirige y codirige diversas tesis doctorales (6) y ha dirigido Proyectos de Fin de Carrera y de Fin de Máster. Ha participado en diversos Proyectos de Innovación y Mejora de la Calidad Docente (PIMCD), tanto en calidad de Director como de miembro del equipo. En investigación destacan sus publicaciones en revistas de reconocido prestigio, monografías en diferentes formatos y contribuciones a congresos nacionales e internacionales. Ha ejercido profesionalmente en calidad de conservador-restaurador de Bienes Culturales para instituciones tanto públicas como privadas: Patrimonio Nacional, Obispados, Ministerios, Museos, Ayuntamientos, etc. 